\title{
Klasifikasi Gelombang Otot Lengan pada Robot Manipulator Menggunakan Support Vector Machine
}

\author{
Muhammad Ja'far Ubaidillah(1), li Munadhif(2), Noorman Rinanto ${ }^{(3)}$ \\ ${ }^{(1,2,3)}$ Program Studi Teknik Otomasi Politeknik Perkapalan Negeri Surabaya \\ (2)iimunadhif.its@gmail.com
}

DOI: https://doi.org/10.21107/rekayasa.v12i2.5406

\begin{abstract}
ABSTRAK
Teknologi robotika semakin berkembang. Banyak orang berinovasi untuk membantu aktivitas mereka, diantaranya membuat robot manipulator untuk mengambil barang di tempat berbahaya atau memindah barang dengan presisi yang sangat tinggi. Pada penelitian ini telah dirancang robot manipulator untuk membantu pasien yang diamputasi pergelangan tangannya agar dapat memegang dan tidak memegang. Sensor Electromyography (EMG) dapat merekam aktivitas listrik yang dihasilkan oleh otot rangka dalam bentuk sinyal yang mempresentasikan gerakan otot. Pada penelitian ini, elektromiogram diekstraksi untuk mendapatkan fitur Root Mean Square (RMS) dan Mean Absolute Value (MAV) kemudian diklasifikasi menggunakan Support Vector Machine (SVM). Metode SVM dipilih karena mampu menemukan hyperplane terbaik sebagai pemisah. Pengendali yang digunakan adalah Arduino yang memerintahkan motor servo untuk menggerakkan robot manipulator sesuai dengan hasil klasifikasi. Penerapan metode Support Vector Machine (SVM) yang bertipe linier memiliki akurasi yang cukup baik dengan keberhasilan $80 \%$ pada pengujian dengan subjek yang telah diambil data sampel dan keberhasilan $60 \%$ pada pengujian dengan subjek yang tidak diambil data sampel.
\end{abstract}

Kata Kunci: Sensor EMG, Otot Lengan, MAV, RMS, SVM, Klasifikasi.

\section{Classification of Muscle Wave Arm on Manipulator Robot Using Support Vector Machine} \begin{abstract}
Robotics technology is growing. Many people innovate to help their activities, including making manipulator robots to take items in dangerous places or move items with very high precision. In this study a manipulator robot was designed to help patients who amputated their wrists to grip and un-grip. Electromyography (EMG) sensors can record electrical activity produced by skeletal muscles in the form of signals that present muscle movements. In this study, the electromyogram was extracted to get the Root Mean Square (RMS) and Mean Absolute Value (MAV) features then classified using Support Vector Machine (SVM). The SVM method was chosen because it was able to find the best hyperplane as a separator. The controller used is Arduino which instructs the servo motor to move the manipulator robot according to the classification results. The application of the Support Vector Machine (SVM) method which has a linear type has a fairly good accuracy with $80 \%$ success in testing with subjects who have taken sample data and $60 \%$ success in testing with subjects who are not taken sample data.
\end{abstract}

Keywords: EMG Sensor, Arm Muscle, MAV, RMS, SVM, Classification.

\section{PENDAHULUAN}

Teknologi robotika semakin berkembang. Banyak orang berinovasi untuk membantu aktivitas mereka, diantaranya membuat robot manipulator untuk mengambil barang di tempat berbahaya atau memindah barang dengan presisi yang sangat tinggi.

Robot lengan juga dapat membantu manusia dalam bidang medis. Khususnya pada pasien yang tertimpa kecelakaan atau pasien yang mempunyai penyakit tertentu yang mengharuskan pasien tersebut untuk amputasi. Robot manipulator

\section{Article History:}

Received: Juni, 28 2019 ; Accepted: September, $29^{\text {th }} 2019$

ISSN: 2502-5325 (Online) Terakreditasi Peringkat 3 oleh Kementerian Riset, Teknologi dan Pendidikan Tinggi (ARJUNA), berdasarkan Keputusan Direktur Jenderal Penguatan Riset dan Pengembangan No: 23/E/KPT/2019 tanggal 8 Agustus 2019 dapat mengganti bagian pergelangan tangan yang telah diamputasi. Kemampuan robot yang dapat bekerja secara biologi maka disebut "Bionik" yang secara estimologi berasal dari kata "Bio" yaitu biologi dan "Nik" yang berarti elektronik (Padillah dkk, 2013). Pada bidang kedokteran yang mempelajari tentang otot manusia dan bidang teknik yang mempelajari tentang mekanik telah bergabung menjadi suatu bidang ilmu baru yaitu Biomekanik yang termasuk juga bagian dari keilmuan Biomedika, dimana Biomeka-

\section{Cite this as:}

Ubaidillah, M.J., Munadhif, I., dan Rinanto, N.(2019). Klasifikasi Gelombang Otot Lengan pada Robot Manipulator Menggunakan Support Vector Machine. Rekayasa, 12(2), 91-97. doi: https://doi.org/10.21107/rekayasa.v12i2.5406

(C) 2019 Muhammad Ja'far Ubaidillah, li Munadhif, 
nik ini adalah bidang yang fokus pengetahuannya mempelajari gerakan pada makhluk hidup, khususnya mempelajari gerakan pada manusia yang keilmuan ini telah menciptakan paradigma baru dalam penerapan teknologi, percepatan pengobatan dan diagnosis mengenai gerak manusia dan menghasilkan teknologi baru yaitu Elektromiograf (Falih, 2017).

Sensor Electromyograph (EMG) merupakan sensor yang dapat merekam aktivitas listrik yang dihasilkan oleh otot rangka. Untuk menghasilkan rekaman yang disebut elektromiogram, sensor EMG mendeteksi potensial listrik yang dihasilkan oleh otot-otot ketika sel-sel elektrik atau neurologis diaktifkan (Padillah dkk, 2013). Data keluaran dari EMG diolah dengan algoritma matematis tertentu sehingga informasi tersebut dapat digunakan dalam pengembangan aplikasi yang berkaitan dengan aktifitas manusia. Keluaran sensor EMG berupa sinyal yang mempresentasikan gerakan otot dan telah banyak dikembangkan di dalam sistem kontrol yaitu bidang game, Industri, Alat bantu medis dan sebagainya (Falih, 2017).

Pada penelitian sebelumnya (Falih,2017) tentang sinyal EMG dan mengklasifikasikannya dengan metode naïve bayes mendapatkan kesimpulan bahwa akurasi yang didapat lebih dari 85\% dan dengan proses eliminasi subyek yang berdasarkan pada pola data raw EMG dari setiap channel memberikan hasil akurasi lebih dari 95,88\%. Kebutuhan pada medis untuk mengganti jari tangan yang telah diamputasi perlu adanya analisis tentang sinyal elektromiogram menggunakan metode Support Vector Machine (SVM) agar dapat menemukan hyperplane terbaik sebagai pemisah.

\section{METODE PENELITIAN}

\section{Perancangan Sistem}

Gambar 1 menunjukkan diagram blok perancangan sistem. Pada diagram tersebut memiliki empat bagian penting yaitu masukan berupa data dari sensor EMG, proses berupa pengendali Arduino, keluaran berupa motor servo, dan perangkat monitoring berupa komputer.

Sensor EMG sebagai pendeteksi sinyal EMG melalui elektrode yang kontak langsung dengan kulit pada lengan bawah. Keluaran modul sensor EMG terhubung dengan pin analog Arduino dan mengirimkan data secara serial ke komputer. Pada komputer, dilakukan pengolahan sinyal untuk memberikan informasi kepada Arduino agar segera memerintahkan motor servo pada lengan robot untuk melakukan gerakan grip atau un-grip. Penggunaan channel pada Arduino memliki fungsi

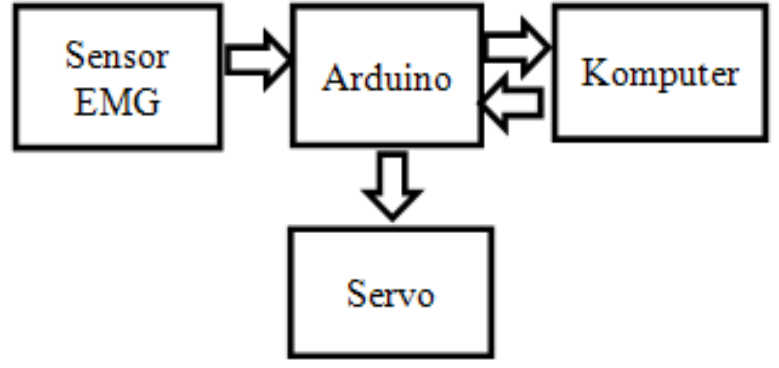

Gambar 1. Diagram blok perancangan sistem

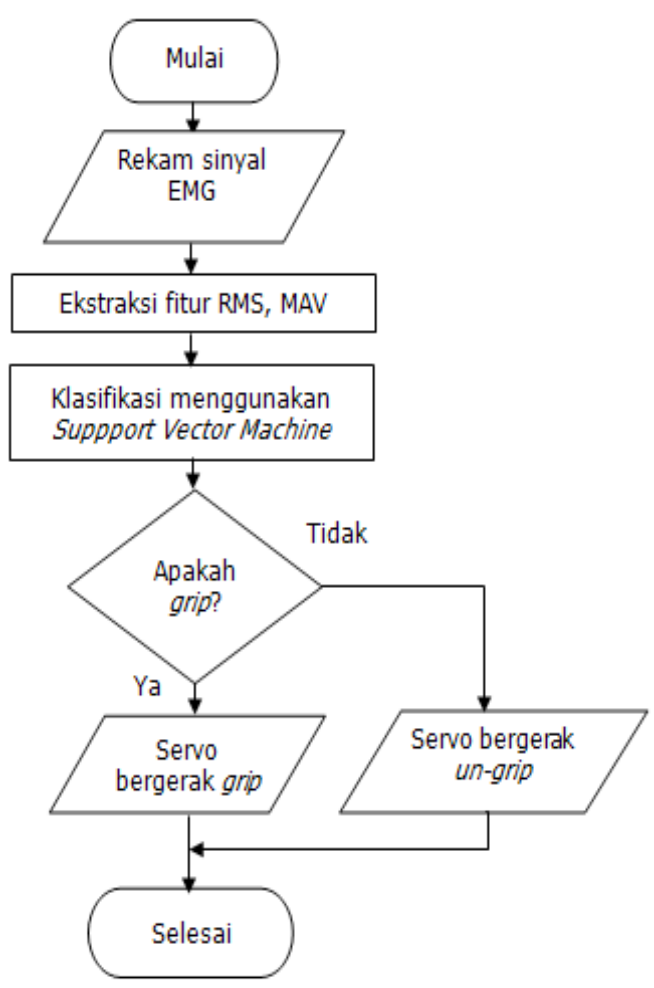

Gambar 2. Diagram alur kerja sistem

masing-masing. Pin A.0 untuk input sensor EMG, Pin 9 untuk motor servo, GND dan 5v untuk sumber tegangan.

\section{Diagram Alur Kerja Sistem}

Pada komputer, sinyal diekstraksi nilai Root Mean Square (RMS) dan Mean Absolute Value (MAV) dari amplitudo sinyal tersebut untuk kemudian digunakan sebagai masukan saat training maupun testing Metode Support Vector Machine (SVM). Seluruh proses perhitungan data dilakukan oleh software MATLAB. Metode Support Vector Machine (SVM) akan mengklasifikasikan jenis sinyal dalam dua kondisi, yaitu grip dan un-grip. Setelah output dari pengklasifikasian yang dilakukan oleh Support Vector Machine (SVM) ini didapatkan, maka komputer mengirimkan perintah ke Arduino. Perintah gerak grip untuk sinyal grip dan perintah gerak un-grip untuk sinyal un-grip. Perintah tersebut digunakan untuk menggerakkan motor servo 
pada lengan robot. Diagram alur kerja sistem ditunjukkan pada gambar 2.

\section{Perancangan dan Pembuatan Hardware}

Gambar 3. merupakan perancangan Hardware. Sensor mendeteksi sinyal EMG melalui elektrode yang dipasang secara langsung pada permukaan luar dari kulit tanpa perlu proses normalisasi sinyal, hal itu karena proses tersebut telah terjadi pada perangkat sensor. Sinyal tersebut akan dibaca melalui pin analog Arduino yang akan dikirimkan ke komputer melalui komunikasi serial. Sinyal diekstraksi untuk mendapatkan parameter-parameter, yaitu nilai Root Mean Square (RMS) dan Mean Absolute Value (MAV) dari amplitudo sinyal agar dapat diklasifikasi dengan metode Support Vector Machine (SVM) saat training maupun testing. Hasil klasifikasi oleh Support Vector Machine (SVM) kemudian dikirim ke Arduino untuk menggerakkan motor servo sebagai penggerak robot manipulator.

\section{Perancangan dan Pembuatan Software}

Pada tahap ini peneliti menggunakan software MATLAB untuk melakukan proses perhitungan dan menampilkan grafik dengan memanfaatkan fitur GUI MATLAB karena mudah dalam penggunaan dan cepat dalam melakukan perhitungan dengan banyak data. GUI MATLAB juga sebagai interface untuk melihat respon sistem saat proses sedang berlangsung.

Gambar 4 merupakan desain interface. Beberapa tombol dan tampilan yang lainnya mempunyai fungsi masing-masing yaitu sebagai berikut:

- Tombol SAMBUNGKAN, untuk menyambungkan software interface dengan Arduino UNO.

- Tombol PUTUSKAN, digunakan untuk memutus koneksi dengan Arduino UNO.

- Tombol GRIP, digunakan untuk mengirim- kan perintah grip ke robot manipulator secara manual.

- Tombol UN-GRIP, digunakan untuk mengirimkan perintah grip ke robot manipulator secara manual.

- LOOP, apabila diaktifkan maka proses pembacaan sinyal, ekstraksi sinyal, klasifikasi, serta gerak robot manipulator akan dilakukan terus menerus.

- TEST, digunakan untuk memulai pembacaan sinyal, ekstraksi sinyal, klasifikasi serta diakhiri dengan gerak robot manipulator.

- NILAI, merupakan nilai realtime dari amplitudo yang terbaca saat ini.

- Tampilan grafik amplitudo sinyal EMG yang terbaca.

- Tabel dari nilai amplitudo sinyal EMG yang terbaca.

- $\quad$ RMS, Nilai dari hasil perhitungan ekstraksi Root Mean Square (RMS) dari amplitudo sinyal EMG.

- $\mathrm{MAV}$, Nilai dari hasil perhitungan ekstraksi Mean Absolute Value (MAV) dari amplitudo sinyal EMG.

- HASIL, menampilkan hasil klasifikasi dari Root Mean Square (RMS) dan Mean Absolute Value (MAV) dari amplitudo sinyal EMG.

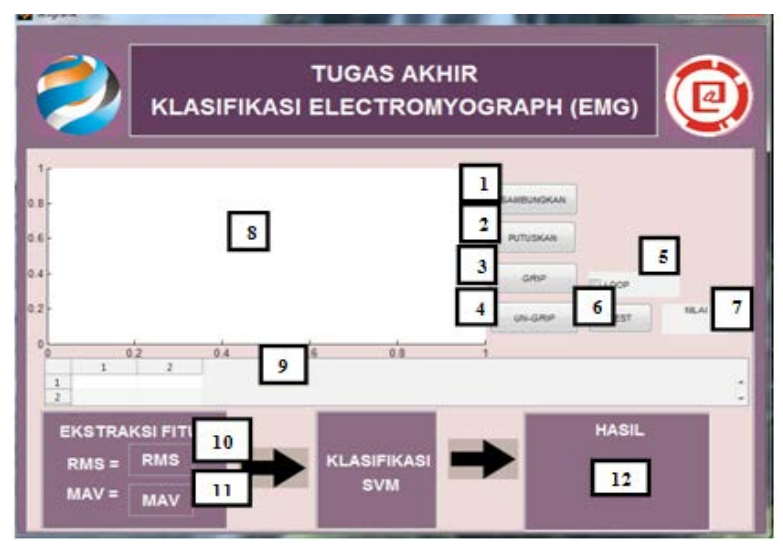

Gambar 4. Desain interface

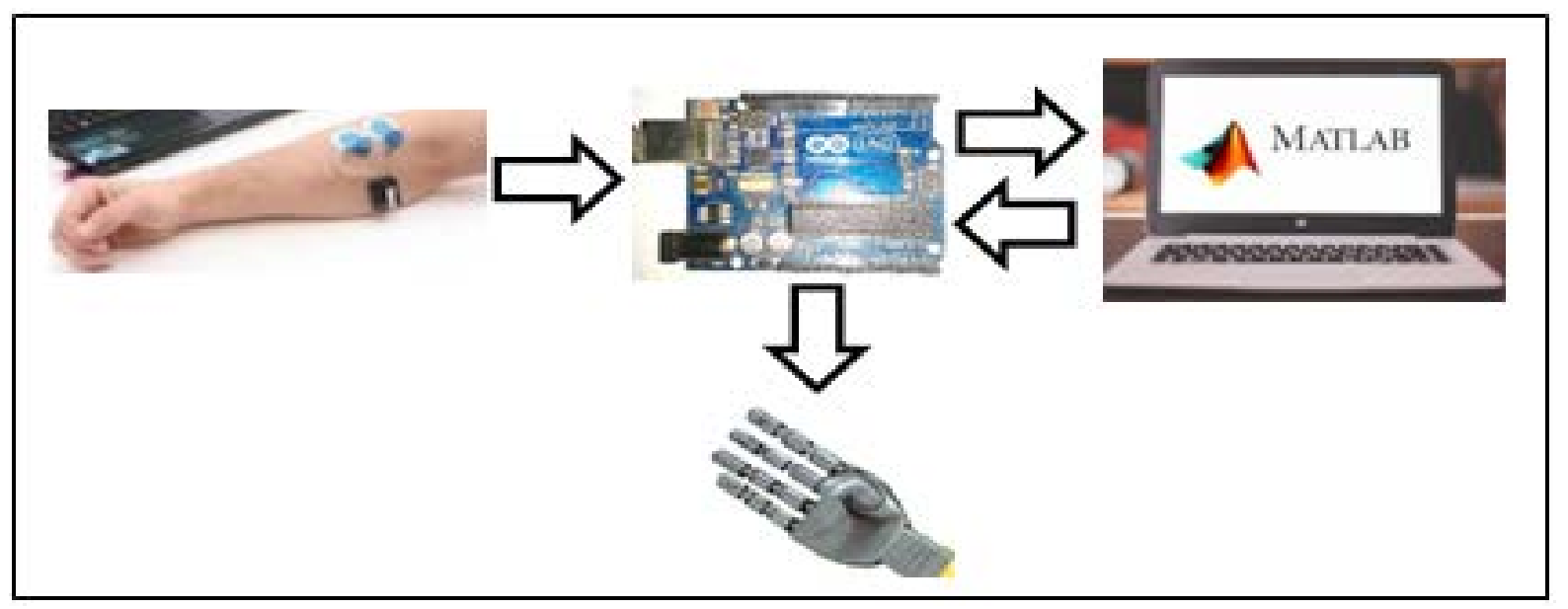

Gambar 3. Perancangan Hardware 


\section{HASIL DAN PEMBAHASAN}

Pada penelitian ini, pengujian pergerakan grip dan un-grip dengan dua kondisi yaitu subjek yang pernah diambil sampel untuk data trining dan subjek yang tidak diambil sampel sebelumnya.

\section{Pengambilan Sampel Gelombang}

Pengambilan sampel gelombang EMG menggunakan Muscle Sensor V3.0. Sensor ini memakai 3 buah elektrode yang terhubung langsung dengan kulit bagian luar pada lengan bawah. 2 buah elektrode sebagai pembaca sinyal EMG dan 1 buah elektrode sebagai referensi.

Penempatan elektrode sensor sangat mempengaruhi hasil dari pembacaan sinyal EMG. Pengambilan sampel gelombang dilakukan pada otot Extensor carpi unlaris pada lengan kanan seperti Gambar 5. Pengambilan sampel dilakukan saat ketiga elektrode telah terpasang dengan tepat. Sinyal un-grip didapatkan dengan merelaksasikan lengan dan seluruh jari tangan kanan sehingga otot tidak sedang kondisi tegang. Sedangkan sinyal grip didapatkan dengan posisi seluruh jari tangan kanan menggenggam dengan kuat. Dengan cara yang sama dan pemasangan sensor dilakukan dengan tepat, pengambilan sensor dilakukan pada 4 orang pria dan 1 orang wanita dengan usia 20 23 tahun, dengan masing-masing orang dilakukan pengambilan sampel un-grip sebanyak 5 kali dan grip sebanyak 5 kali. Maka didapat 50 data yang akan diekstraksi untuk digunakan sebagai data training.

Gambar 6 merupakan gambar sinyal EMG yang didapat dari lengan bawah jari tangan dalam kondisi un-grip. Gambar 7 juga merupakan sinyal EMG yang didapat dari lengan bawah jari tangan dalam kondisi un-grip. Dapat dicermati bahwa ketika lengan bawah jari tangan dalam kondisi ungrip, sinyal yang didapatkan mempunyai range amplitudo $300 \mathrm{mv}$ hingga $500 \mathrm{mv}$. Selanjutnya dilakukan pengambilan sampel dari lengan bawah jari tangan dalam kondisi grip.

Gambar 8 merupakan gambar sinyal EMG yang didapat dari lengan bawah jari tangan dalam kondisi grip. Sedangkan Gambar 9 juga merupakan sinyal EMG yang didapat dari lengan bawah jari tangan dalam kondisi grip. Dapat dicermati bahwa ketika lengan bawah jari tangan dalam kondisi grip, sinyal yang didapatkan mempunyai range amplitudo $700 \mathrm{mv}$ hingga $1000 \mathrm{mv}$.

\section{Ekstraksi Gelombang EMG Fitur Root Mean Square (RMS)}

Fitur Root Mean Square (RMS) dari amplitudo sin- yal EMG ini akan digunakan sebagai data training dan data testing. Amplitudo yang diambil adalah seluruh dari amplitudo yang telah didapatkan. Untuk melakukan perhitungan fitur RMS ini dapat

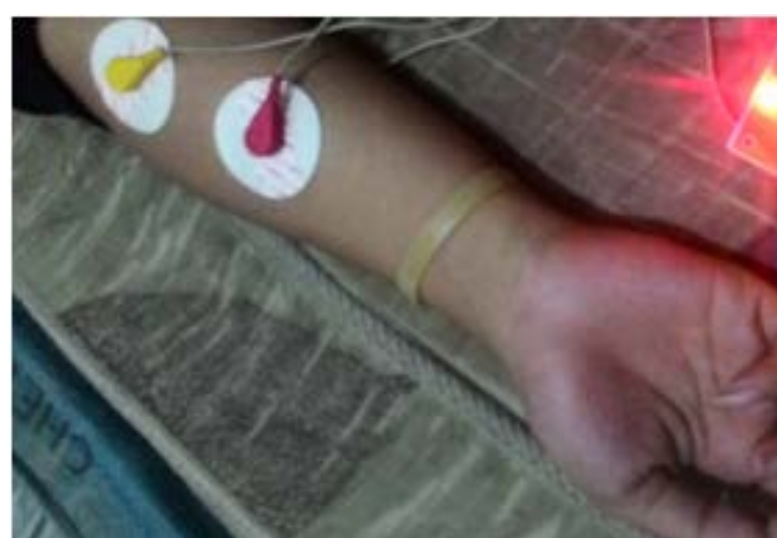

Gambar 5. Pengambilan sampel

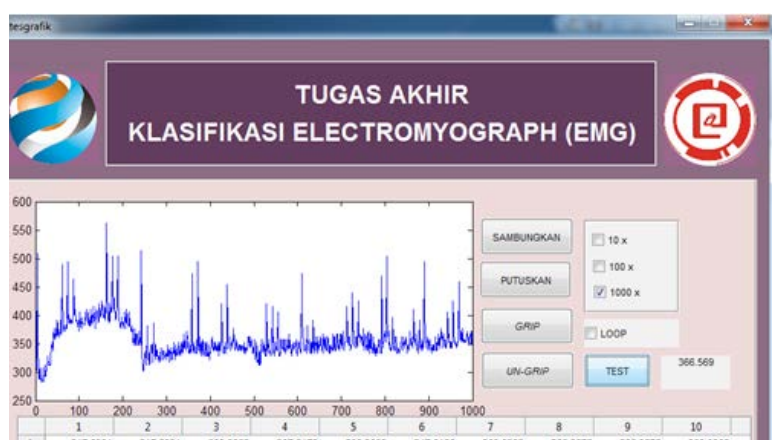

Gambar 6. Sinyal EMG kondisi un-grip (1)

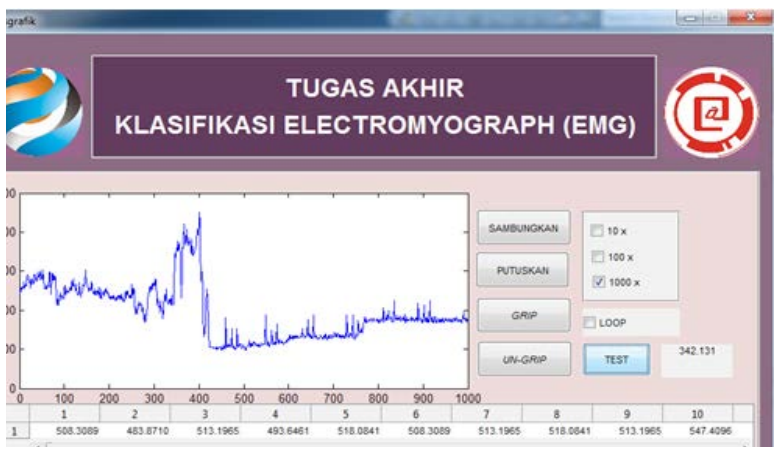

Gambar 7. Sinyal EMG kondisi un-grip (2)

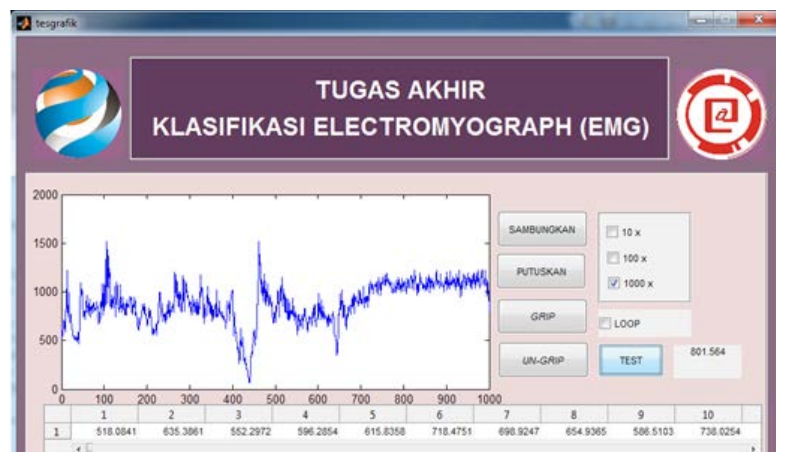

Gambar 8. Sinyal EMG kondisi grip (1) 


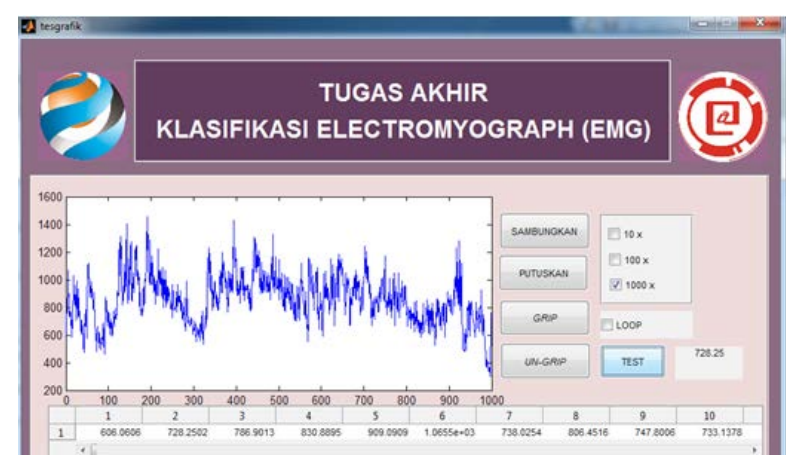

Gambar 9. Sinyal EMG kondisi grip (2) menggunakan Persamaan 1.

$$
R M S=\sqrt{\frac{1}{N} \sum_{i=1}^{N} x_{i^{2}}}
$$

Dimana $\mathrm{N}$ adalah banyaknya data dan nilai i adalah data.

a. Ekstraksi Gelombang EMG Fitur Mean Absolute Value (MAV)

Fitur Mean Absolute Value (MAV) dari amplitudo sinyal EMG ini juga akan digunakan sebagai data training dan data testing. Amplitudo yang diambil adalah seluruh dari amplitudo yang telah didapatkan. Untuk melakukan perhitungan fitur MAV ini dapat menggunakan Persamaan 2.

$$
M A V=\frac{1}{N} \sum_{n=1}^{N}\left|x_{n}\right|
$$

Dimana $\mathrm{N}$ adalah banyaknya data dan nilai i adalah data .

\section{SVM dengan Data Training}

Penerapan metode SVM pada penelitian ini menggunakan dua input dan satu kelas output 1 dan 0,1 mewakili kelas +1 dan 0 mewakili kelas -1 . Data input yang digunakan sebagai data training dan data testing pada metode SVM ini adalah fitur Root Mean Square (RMS) dan fitur Mean Absolute Value (MAV) dari amplitudo sinyal EMG.

\section{Pengujian Sistem Secara Keseluruhan}

Pengujian sistem meliputi pengujian metode dan aktuator yang digunakan. Pengujian metode yang digunakan adalah pengujian dengan data yang telah didapatkan dari pengambilan sampel dengan data yang belum pernah dilakukan pengambilan sampel dan kemudian dihitung presentase keberhasilan metode dalam melakukan mengkla-
Tabel 1. Hasil pengujian kondisi pertama

\begin{tabular}{cccccc}
\hline No. & Kondisi & Target & Hasil & Error & Keterangan \\
\hline 1 & Un-grip & 0 & 0 & $0 \%$ & Benar \\
2 & Un-grip & 0 & 0 & $0 \%$ & Benar \\
3 & Un-grip & 0 & 0 & $0 \%$ & Benar \\
4 & Un-grip & 0 & 1 & $100 \%$ & Salah \\
5 & Un-grip & 0 & 0 & $0 \%$ & Benar \\
6 & Grip & 1 & 1 & $0 \%$ & Benar \\
7 & Grip & 1 & 0 & $100 \%$ & Salah \\
8 & Grip & 1 & 1 & $0 \%$ & Benar \\
9 & Grip & 1 & 1 & $0 \%$ & Benar \\
10 & Grip & 1 & 1 & $0 \%$ & Benar \\
\hline
\end{tabular}

sifikasikan. Pengujian aktuator yang dilakukan adalah pengujian lengan robot manipulator yang digerakkan oleh sebuah motor servo untuk merepresentasikan hasil klasifikasi. Gerakan robot manipulator yang digunakan pada Tugas Akhir ini mempunyai dua gerakan, yaitu grip untuk hasil klasifikasi jari tangan menggenggam kuat dan ungrip untuk hasil klasifikasi jari tangan relaks atau kondisi otot tidak tegang. Pengujian metode yang dilakukan mempunyai 2 kondisi yaitu:

1. Pada subjek yang pernah diambil sampel untuk data training, dalam hal ini adalah peneliti yang telah terlatih memasang elektrode kira-kira dalam waktu 4 bulan dan telah diambil sampel untuk data training.

2. Pada subjek yang tidak diambil sampel sebelumnya.

Pada pengujian kondisi pertama, pengujian dilakukan sebanyak 10 kali dengan 5 kali percobaan grip dan 5 kali percobaan un-grip. Pengujian ini dilakukan oleh peneliti dengan menggerakkan jari tangan kanan grip dan un-grip. Hasil pengujian kondisi pertama dapat ditunjukkan pada tabel 1 .

Berdasarkan Tabel 1, presentase keberhasilan pengujian pada kondisi pertama ini yaitu $80 \%$. Dapat disimpulkan bahwa metode yang digunakan cukup akurat dalam melakukan klasifikasi dengan data yang telah diambil sampel.

Pada pengujian kondisi kedua, pengujian dilakukan sebanyak 10 kali dengan 5 kali percobaan grip dan 5 kali percobaan un-grip. Pengujian ini dilakukan oleh peneliti dengan menggerakkan jari tangan kanan grip dan un-grip. Hasil pengujian kondisi pertama dapat dilihat pada Tabel 2 berikut.

Berdasarkan Tabel 2, presentase keberhasilan pengujian pada kondisi kedua ini yaitu 60\%. Dapat disimpulkan bahwa metode yang digunakan cukup 
96 | Ubaidillah, M.J. dkk., Klasifikasi Gelombang Otot Lengan pada Robot Manipulator...

Tabel 2. Hasil pengujian kondisi kedua

\begin{tabular}{cccccc}
\hline No. & Kondisi & Target & Hasil & Error & Keterangan \\
\hline 1 & Un-grip & 0 & 1 & $100 \%$ & Salah \\
2 & Un-grip & 0 & 0 & $0 \%$ & Benar \\
3 & Un-grip & 0 & 1 & $100 \%$ & Salah \\
4 & Un-grip & 0 & 0 & $0 \%$ & Benar \\
5 & Un-grip & 0 & 0 & $0 \%$ & Benar \\
6 & Grip & 1 & 1 & $0 \%$ & Benar \\
7 & Grip & 1 & 0 & $100 \%$ & Salah \\
8 & Grip & 1 & 1 & $0 \%$ & Benar \\
9 & Grip & 1 & 1 & $0 \%$ & Benar \\
10 & Grip & 1 & 0 & $100 \%$ & Salah \\
\hline
\end{tabular}

akurat dalam melakukan klasifikasi dengan data yang belum diambil sampel. Dari pengujian ini didapatkan bahwa rata-rata kecepatan respon robot manipulator adalah 3 detik.

\section{KESIMPULAN}

Berdasarkan hasil keseluruhan yang telah didapatkan setelah dilakukan analisis dan pengujian pada sistem yang telah dibuat, maka didapatkan kesimpulan bahwa: Muscle Sensor V3.0 mampu digunakan untuk pengambilan sinyal EMG dalam kondisi grip dan un-grip pada lengan tangan kanan peneliti, namun pembacaan sensor tidak terlalu akurat pada lengan tangan kanan yang mempunyai otot yang tidak teralalu nampak. Sinyal yang terbaca oleh sensor EMG yang berdomain waktu dapat diekstraksi menggunakan fitur Root Mean Square (RMS) dan Mean Absolute Value (MAV). Metode Support Vector Machine (SVM) tipe linier yang menggunakan masukan dari RMS dan MAV mampu mengklasifikasikan kondisi grip dan ungrip dengan baik. Penerapan metode Support Vector Machine (SVM) tipe linier memiliki akurasi yang cukup baik dengan tingkat keberhasilan $80 \%$ pada pengujian dengan subjek yang telah diambil data sampel dan mendapat tingkat keberhasilan $60 \%$ pada pengujian dengan subjek yang tidak diambil data sampel.

\section{DAFTAR PUSTAKA}

Bhavsar, H., Mahesh H. P. (2012)."Review on Support Vector Machine for Data Classification". Vol 1, Issue 10

Falih, A. D. I. (2017)."Klasifikasi Sinyal EMG Dari Otot Lengan Sebagai Media Kontrol Menggunakan Naïve Bayes" (Tesis). Surabaya. Institut Teknologi Sepuluh Nopember.
Fiska, R. R. (2017). Penerapan Teknik Data Mining dengan Metode Support Vector Machine (SVM) untuk Memprediksi Siswa yang Berpeluang Drop Out. Jaringan Sistem Informasi Robotik Vol. 1,No. 01, 42-51.

Lee, J., Kim J., Park J. (2013). "Classification of grip configuration using surface EMG", in 2013 13th International Conference on Control, Automation and Systems (ICCAS 2013).

Muis, I. A., Muhammad A. (2015). "Penerapan Metode Support Vector Machine (SVM) Menggunakan Kernel Radial Basis Function (RBF) Pada Klasifikasi Tweet", Vol.12 No.2

Mustiadi, I., Thomas S. W., Indah S., (2012). "Analisis Ekstraksi Ciri Sinyal EMG Menggunakan Wavelet Discrete Transform", Yogyakarta.

Nugraha, D.W. (2011). "Pengendalian Robot Yang Memiliki Lima Derajat Kebebasan", IImiah Foristek, 1(1): p. 22.

Padillah, H. A., Arif G., Wahyuni K. (2013). "Kontrol Wireless Bionik Robot Jari Tangan Menggunakan Arduino", Vol I, No. 2.

Paul, Y., Goyal V., Jaswal R.A. (2017). "Comparative analysis between SVM \& KNN classifier for EMG signal classification on elementary time domain features", in 2017 4th International Conference on Signal Processing, Computing and Control (ISPCC).

Phinyomark, A., Phukpattaranont P., Limsakul C. (2012). "Feature Reduction and Selection for EMG Signal Classification", Vol. 39. 7420-7431.

Rahman, M.M., Rosly M.H.M. (2016). "Gripping Motion of Artificial Hand Using EMG Signal", in 2016 International Conference on Computer and Communication Engineering (ICCCE).

Rekhi, N. S., Arora A. S., Singh S., Singh D. (2009). "Multi-Class SVM Classification of Surface EMG Signal for Upper Limb Function", in 2009 3rd International Conference on Bioinformatics and Biomedical Engineering.

Rusmanto. (2016). "Akuisisi Data Sinyal EMG di Lengan Tangan dengan Sensor Surface Electrode Menggunakan Mikrokontroler Arduino Uno" (Tugas Akhir). Semarang: Universitas Dian Nuswantoro. 
She, Q., Luo Z., Meng M. Xu P. (2010). "Multiple kernel learning SVM-based EMG pattern classification for lower limb control", in 2010 11th International Conference on Control Automation Robotics \& Vision.

Subhash, K.M., Pournami P.N., Joseph P.K. (2017). "Census transform based feature extraction of EMG signals for neuromuscular disease classification", in 2017 IEEE 15th Student Conference on Research and Development (SCOReD).

Technologies, A. (2013). "Three-lead Differential Muscle/ Electromyography Sensor for Microcontroller Applications" (Datasheet).
Tong, S., Daphne K. (2001). "Support Vector Machine Active Learning with Applications to Text Classification". USA.

Wibawa, A. D., Verdonschot N., Burgerhof J. G. M., Purnama I. K. E., Andersen M. S., Halbertsma J. P. K., Diercks R. L., Verkerke G. J. (2013) "A validation study on muscle activity prediction of a lower limb musculoskeletal model using EMG during normal walking", in 2013 3rd International Conference on Instrumentation, Communications, Information Technology and Biomedical Engineering (IClCl-BME). 